\title{
HOUSEHOLD PARTICIPATION IN RECYCLING PROGRAMS: A CASE STUDY FROM MALAYSIA
}

\author{
Azilah M Akil ${ }^{1}$, Foziah Johar ${ }^{2}$, Ho Chin Siong ${ }^{3}$
}

Diterima: 5 Januari 2015 Disetujui 30 Maret 2015

\begin{abstract}
The increase in per capita income and rapid urbanization, have contributed significantly to changes in consumption behaviour leading to increased waste generation. Waste disposed to landfill sites is fast becoming unfeasible thus requiring a more effective management of waste material involving waste reduction, reuse and recycling. The success of recycling program, however, is largely dependent on household participation activities which are essentially behaviour driven. The recycling performance of Malaysian households is still low as it stands at 5.5\% compared to Singapore and Vietnam which are $56 \%$ and $22 \%$ respectively. This study examines recycling behaviour among households and the influence of socioeconomic, demographic and behavioural characteristics on households' participation in recycling program in Malaysia. A sample of 300 randomly selected household were surveyed. The findings revealed that most of the households $(70 \%)$ claim that they are practicing recycling particularly types of paper and old clothes. The factors of participation in recycling show equal results both for environmental concerns and economic benefits. Those who did not participate in recycling, listed household issues or behaviour, namely lack of time and materials to recycle, inconvenient, lack of space, lack of facilities and information as well as laziness, as barriers. The paper finally highlights the factors which can encourage household to be involved in recycling and give recommendations to the authorities in terms of facilities and infrastructures to facilitate the program.
\end{abstract}

Keywords: household participation, recycling, behavior

\section{Introduction}

Solid waste disposal is fast becoming a critical problem to the local authorities throughout the world in term of both its management logistic and cost (Berglund and Matti 2006) (Berglund, 2006, Vencatasawmy et al., 2000 ). The amount of solid waste generated is found to have a positive correlation with income levels and urbanization, as income rises and level of urbanization economies increases, more solid waste per capita is produced (Omran. et. al, 2009). In 1998, Malaysia generated about 5.5million tonnes of SW of which a quarter was produced in the Klang Valley alone, the most affluent area in Malaysia. With a population of over 26 million in 2007, about 17,000 tonnes of domestic waste were generated daily. In 2012, an estimated 25,000 tonnes of waste generated per

\footnotetext{
1 Department of Urban \& Regional Planning, Universiti Teknologi Malaysia, Johor Bahru, Malaysia,

2 Centre for Innovative Planning and Development (CiPD), Universiti Teknologi Malaysia, Johor Bahru, Malaysia,

3 Department of Urban \& Regional Planning, Universiti Teknologi Malaysia
} 
day in Peninsular Malaysia. Annually waste generation increased by $3 \%$ which is of critical concern especially in terms of the amount and composition. Malaysian solid waste contains a high concentration of organic waste and consequently has a high moisture content and a bulk density above $200 \mathrm{~kg} / \mathrm{m}^{2}$. The increasing trend of solid waste generation in Malaysia has four contributing factors apparently similar to other developing countries.

They include high rate of population growth, rapid urbanisation, high proportion of urban population, changing profile of the population characterised by high ratio of population dependence, thus require more facilities to be provided and lastly rapid economic growth contributing to higher income per capita (Zamali, Mohd et al. 2009). There are 165 operational landfills across Malaysia catering to 95\% of Malaysian waste. Out of this, only 8 sanitary landfills are operational while 11 are under various stages of implementation and construction. Other landfills are nearing their maximum capacity and these would be an enormous challenge due to the environmental impact of closed landfill. At the same time, the local authorities are having difficulties finding suitable landfill sites because of land scarcity nearby settlement area. A sustainable solid waste management system called for preventional efforts to generate unnecessary waste which are related to the human habits, environmental awareness and responsibility (Commision of the European Communities. 1992). A holistic and integrated effort must be made to minimize the quantity of solid waste generated and this requires the cooperation and full participation of those who generate the waste including the general public. Finally, if both measures cannot be avoided, waste will be disposed by the following order; (i) combusting, (ii) incineration, and (iii) land filling.

To address the increasing amount in waste generation the Malaysian government launched several public information campaigns to establish awareness and to create environmental consciousness among the general public. It started with the Action Plan for a Beautiful and Clean (ABC) Malaysia 1988 followed by series of recycling campaigns. However, the campaigns failed to motivate the community to respond positively. The recycling rate for Malaysia was only 5\% in 2002 and increased slightly to 5.5\% in 2006 and 2008. Compared to neighbouring countries in South-East Asia this is far too low. Singapore recorded a $56 \%$ recycling rate and Philippines at $12 \%$ (Periathamby et.al, 2009). In 2007, the government introduced the Solid Waste and Public Cleansing Management Act. The implementation and enforcement of the 3 Rs are also listed in the Act, in which solid waste generators are required to reduce the generation of solid waste; to use environmentally friendly materials; to limit the generation, import, use, discharge, and disposal of specified products; to implement coding and labeling on products to promote recycling; and to utilize the $3 \mathrm{R}$ to reduce the adverse impacts on the environment. In line with the Act,thegGovernment will be implementing the mandatory separation of solid waste at source in 2015.

Nevertheless, concern and awareness among the public in Malaysia have not evolved in parallel with the living standards and therefore participation towards sustainable waste management through 3Rs is severely lacking. Studies have shown that recycling behaviour of householders and their other environmental behaviours are complex and varied. Investigations by a large number of researchers have revealed that the predictors of recycling behaviour comprise a large set of variables (Coggins, 1994; McDonald and Ball, 1998; Tucker, 1999). This study aims to investigate the similarity of the local factor of barrier and motives established in previous literatures in households waste recycling activities. This study examines recycling behaviour among households and the influence of socioeconomic, demographic and behavioural characteristics on households' participation in recycling program in Malaysia. This paper will next examines existing literatures on recycling practices before describing the survey and its result. Finally,conclusions from the analysis are drawn and some concluding remarks are made. 


\section{Literature Review}

Recycling is a one of the treatment can reduce the amount of waste that goes to incineration or landfills. It enables the creation of new products from old materials, thus benefiting both the environment and the economy (Vicente and Reis, 2008). Boldero (1995) defined recycling is a behaviour which requires considerable effort on the part of the individuals as household waste must be sorted, prepared and stored but the decision and factors may be taken into consideration. Beneficial use of waste depends on efficient collection and separation. However, unless the waste is separated into well-defined material, the environmental potential of recycling strategies cannot be fully realised (Ayres, 1997; Krook et al., 2007; Rejinders, 2000). Attitudes are the major contributor to recycling behaviour. These attitudes are influenced by having the appropriate opportunities, facilities and knowledge to recycle, and by not being deterred by the issues of physically recycling for example time, space and inconvenience (Tonglet, Phillips et al. 2004). An effective study of strategies aiming to increase participation in recycling involves understanding the factors that influence decision and barriers to recycle.

Several empirical studies showed that recycling behavior is influenced by the extrinsic and intrinsic factors of individuals towards recycling. (Ryan and Deci 2000) defined intrinsic factors as the doing of an activity for its inherent satisfactions rather than for some separable consequence. Intrinsic factors are defined as personal satisfaction or altruism, awareness or knowledge about environmental issues and perceived effectiveness of individual action (Garces, Lafuente et al. 2002). While extrinsic motivation, defined as a construct that pertains whenever an activity is done in order to attain some separable outcomes, extrinsic motivation is driven by monetary rewards, social and family influence, and prompts as well as information about how to participate the recycling program (Ryan and Deci, 2000).

Early study on factors influencing behaviour was focused on monetary reinforces to initiate and sustain the desire to recycle (Oskamp, Harrington et al. 1991) found that recyclers reported monetary concerns as their main incentives but will not do so without if there is no monetary value. De Young (1986) pointed that recycling behaviour was related to personal satisfaction in being frugal, being self-sufficient and participating in a program where one's actions can make a difference.

While numerous studies have attempted to explain barriers factors related to household waste recycling. (McDonald and Oates 2003) classified four main barriers which were believed to be the main obstacles for those who are not participating in recycling scheme. The four main issues are efforts, information, context and incentives. Specifically the barriers are insufficient paper, no space to locate bin, etc. A review by (Jesson and Stone 2009) showed that past studies had focused barriers to recycling household waste in UK. The findings shows that the reason why people do not participate in recycling can be allocated into four categories namely: household /individual behaviour; services or local situation; attitudes or motivation and information or knowledge.

\section{The Study Area}

Iskandar Malaysia Region, located in Johor State to the south of Peninsular of Malaysia has been chosen as the study area. Having the economic and locational advantages due to its proximity to Singapore and the space to grow, the South Johore Economic Region (SJER) was identified as one of five future economic corridors in the country. Iskandar Malaysia has been identified as one of the catalysts for GDP growth through high-impact developments. Since its formation in 2006, through public-private urban renewal and new urban/suburban projects, the city-region has experienced spatially diffused, low-density sprawl into pre-existing rural land covering an area of over 2217 square km. About 1.35 million residents live in Iskandar Malaysia Region in year 2010 and expected to increase to 3 million in year 2025. Figure 1 shows the study area and the information on 
the population size and waste generated in 2010 and projected amount by 2025. According to the local authority area, IM consists the area covered by the local authorities of Johor Bahru City Council (MBJB) and Central Johor Bahru Municipal Council (MPJBT), Kulai Municipal Council (MPKu), Pasir Gudang Municipal Council (MPPG) and some parts of Pontian District Council. It is located in southern of Johor Bahru District. The Comprehensive Development Plan (CDP) has been formulated to provide the strategic framework of visions, principles, development strategies, goals and key directions for the region that is livable for its people, in which they can carry out daily activities with pleasure, pride, and harmony. Its vision of a 'strong, sustainable conurbation of international standing' is read as a commitment 'To create a sustainable conurbation which has taken into consideration the needs of all its stakeholders and subsequently enhance the quality of its community's life without compromising the ecology of the environment. It also commits to creating a livable and attractive environment for residents, businesses and visitors. The Iskandar Vision largely revolved around physical development schematized into five flagship zones within SJER:

a. Johor Bahru (JB) City Centre, the core of the SJER conurbation, to develop as the financial centre for the region;

b. Nusajaya, a green zone to the west of JB, to be converted to residential, light-industry, and tertiary uses;

c. Western Gate and Development, to strengthen the rapidly growing area around the Port of Tanjung Pelepas (PTP);

d. Eastern Gate Development, to strengthen and redevelop the brownfield area around Pasir Gudang Port and its heavy industries; and

e. Senai-Skudai, two cities located to the north of JB, to sustain the need of the region for quaternary infrastructure (universities, airports etc.).

\section{Methodology}

A total of 304 households were randomly sampled. The direct, face-to-face interview was employed in this study. Residents of the study areas come from various socioeconomic backgrounds and live in planned, mixed residential developments. The survey was conducted using a structured questionnaire that covered two basic principles; a) behaviour of recycling; b) motive and barrier in. The first part includes routine questions about background variables such as age, gender, family status, income, etc. Data were statistically analysed using the SPSS.

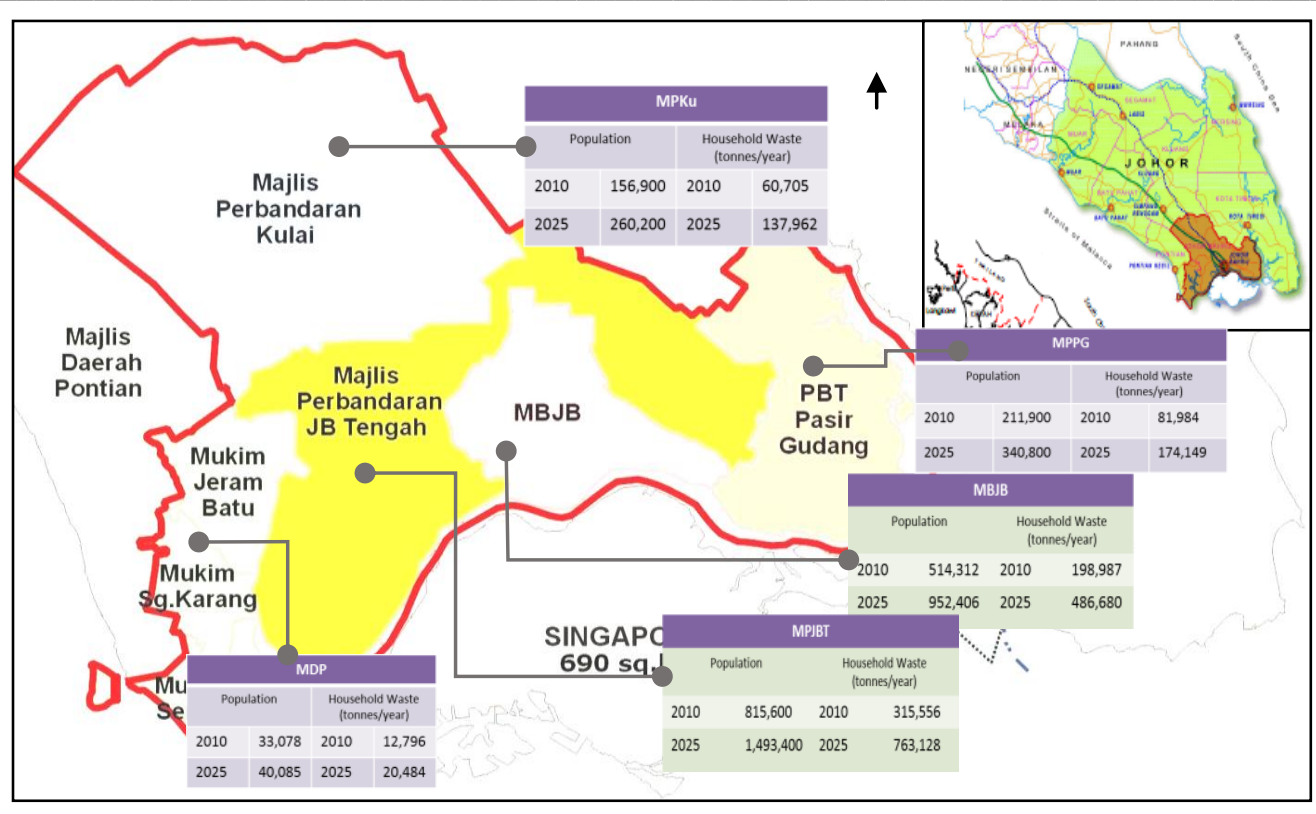

Figure 1. Study Area 


\section{Results}

\section{Profile of respondents}

Socio demographic characteristics of the respondent are summarized in Table 1 . The study area has a multi-racial and multi-religious community, which reflects the totality of Malaysian society. In this study area the number of men are more than women, a similar pattern observed for overall population in 2010 census of Malaysia. The average age of the respondents is 41 years. The majority of the age categories in the study area consists of adults and elderly. Most of the respondents are married.

A major proportion of the respondents have a secondary school education (60.4\%) followed by $15.5 \%$ with diplomas. Only $7.3 \%$ have a bachelor degree, $13 \%$ had reached primary level and 3.0\% have not attended formal education. On average the monthly household income of the respondents was RM3387.00 which is slightly lower than the mean monthly household income in urban area of Johor which is RM4,658 and the national average which is RM5000 in year 2012 (Statistical Department, 2012). The percentage of households in the income class of RM5,000 and above shows the highest percentage (20\%). This is followed by the group with an average income of RM2000 to RM2999 and RM3000 to RM3500 (19.8\%). Meanwhile, the percentage of households earning below RM2,000 is $14.8 \%$ leaving only $0.6 \%$ in the income below RM 1,000 . The majority $(80 \%)$ of the respondents were the owner of the house and the average of household size is 4.39 persons per house.

Table 1: Profile of demographics

\begin{tabular}{|c|c|}
\hline Race & $\%$ \\
\hline Malay & 69.8 \\
\hline Chinese & 20.5 \\
\hline Indian & 8.4 \\
\hline Others & 1.3 \\
\hline Total & 100.0 \\
\hline Religion & $\%$ \\
\hline Muslim & 71.1 \\
\hline Buddhism & 18.4 \\
\hline Hinduism & 7.9 \\
\hline Christianity & 2.0 \\
\hline Others & 0.7 \\
\hline Total & 100.0 \\
\hline Gender & $\%$ \\
\hline Male & 52.6 \\
\hline Female & 47.4 \\
\hline Total & 100.0 \\
\hline Age & $\%$ \\
\hline Below 18 & .3 \\
\hline $18-24$ & 3.0 \\
\hline $25-34$ & 25.7 \\
\hline $35-44$ & 27.7 \\
\hline $45-54$ & 25.4 \\
\hline $55-64$ & 14.5 \\
\hline$>65$ & 3.3 \\
\hline \multirow[t]{2}{*}{ Total } & 100.0 \\
\hline & Mean : 41 years old \\
\hline Marital Status & $\%$ \\
\hline Never married & 6.9 \\
\hline Married & 89.1 \\
\hline Widowed & 2.6 \\
\hline Divorced & 1.3 \\
\hline Total & 100.0 \\
\hline Education & $\%$ \\
\hline Have not attended school & 3.0 \\
\hline Primay school & 13.9 \\
\hline Secondary school & 60.4 \\
\hline Diploma & 15.5 \\
\hline Bachelor degree & 7.3 \\
\hline
\end{tabular}




\begin{tabular}{|c|c|}
\hline Race & $\%$ \\
\hline Total & 100.0 \\
\hline $\begin{array}{l}\text { Household monthly } \\
\text { (RM) }\end{array}$ & income \\
\hline Below RM499 & 0.3 \\
\hline RM500-999 & 0.3 \\
\hline RM1000-1499 & 2.3 \\
\hline RM1500-1999 & 12.5 \\
\hline RM2000-2499 & 19.8 \\
\hline RM2500-2999 & 10.6 \\
\hline RM3000-3499 & 19.8 \\
\hline RM3500-3999 & 5.3 \\
\hline RM4000-4499 & 7.9 \\
\hline RM4500-4999 & 1.0 \\
\hline RM5000 above & 20.1 \\
\hline \multirow[t]{2}{*}{ Total } & 100.0 \\
\hline & Median: RM3000 Mean: RM3387.38 \\
\hline Ownership of the house & $\%$ \\
\hline Owned & 81.5 \\
\hline Rent & 17.8 \\
\hline Others (Quarters) & 0.7 \\
\hline Total & 100.0 \\
\hline Household Size & $\%$ \\
\hline Small (1-3) & 32.0 \\
\hline Medium (4-6) & 60.1 \\
\hline Large (7 and above) & 7.9 \\
\hline Total & 100.0 \\
\hline Mean : 4.39 persons & \\
\hline
\end{tabular}

Source: IRDA

\section{Current waste disposal practice}

Currently household are required to place their waste bags in waste bins in front of their houses. The collectors collect the wastes twice or thrice a week. Households are required to pay collection services as part of the annual assessment tax set by the local authorities with service provider. Nevertheless, not all waste is disposed in such manner. When asked whether they recycle or not, $60 \%$ said some kind of recycling were carried out, while the remaining $40 \%$ admitted that they did not recycle their waste.

\section{Recycling Practice}

Almost $60.1 \%$ claimed they are practicing the recycling at the home. For those who recycle, Figure 2.shows that handling method of recycling vary with material types The analysis on method of recycling demonstrated two types of recyclable material were highest recycled. A majority of respondents $(70 \%)$ do recycle basic recyclable materials namely papers and old clothes. This is followed by material type of aluminium (55.7\%), types of plastic $(48.1 \%)$ and glasses $(47 \%)$. It should be pointed out that at present there is no convenient or formal recycling network in the neighbourhoods that were surveyed. Nevertheless, in response to this situation, recycle materials are often sold to door to door private collectors or Non Governments Organization (NGOs) using various modes especially by lorry or van. A matter of concern is the fact, that most households dispose their wastes such as polystyrene, plastics, glass and food waste into waste bin without separation. 


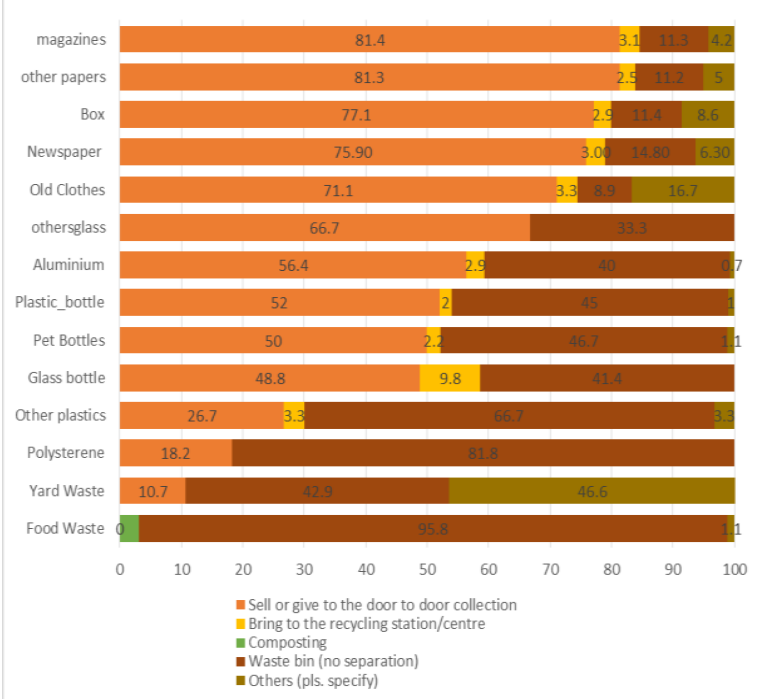

Figure 2. Disposal method by materials

The respondents were also asked to rank their frequency of recycling. Figure 3, shows that $34 \%$ of the respondents claimed that they have always separated their waste according to the categories while $13 \%$ claimed they always recycled. This is quite encouraging. An almost similar proportion of respondents (11\% to 14\%) are in the category of infrequent recycling but $28 \%$ never practiced.

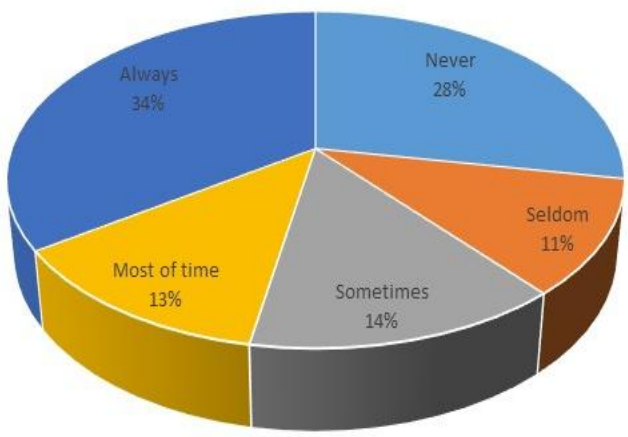

Figure 3. Separating solid waste according to their category (recyclable and non- recyclable

The present study shows a positive relationship between age and frequency of recycling. According to figure 4, people in the age group of 55 and above (45\%) are found to be more active in recycling compared to the younger ones. This is consistent with the findings from many other studies which also reveal that older households are more likely to participate in recycling activities (Singhirunnusorn, Donlakorn et al. 2012), (Bowman, Goodwin et al. 1998); Meneses and Palacio, 2005; Saphores et al., 2006). This is contrary to common expectation that younger people are likely to be more involved in recycling based on the assumption that they are more environmental conscious. Some studies suggest that older people recycle simply because they have more time on their hands; after all, recycling is a time-intensive activity (Martin et al. 2006, Bruvoll et al. 2002). 


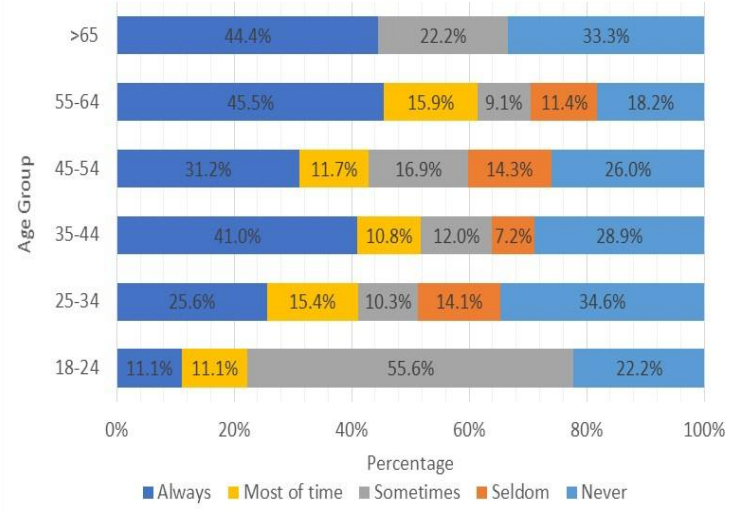

Figure 4: Frequency of separating solid waste by age group

The findings of this study on the relationship between income and education with recycling activities does not concur with previous research. Figure 5 shows that people without formal education and primary school group are more involved in separating waste compared to those with high education level. This does not support the findings of (Callan and Thomas 1997) and (Duggal , V.G. et al. 1991) who inferred a positive correlation between income, education levels and recycling. Other studies such as Ferrara and Missios (2004) found that people with less income recycle more newspaper and plastic while people with post-graduate education recycled newspaper, as well as glass and aluminium. This is consistent with (Jenkins, Martinez et al. 2003) who found more newspapers are recycled by higher income people and those attaining higher level of education and they were also recycling glass and aluminium. The situation is different in the present study. A possible explanation for this is the financial benefit gained by the respondents who get paid by the collectors according to the weight of the material. Among the high income earners (RM10000-RM14999), while 25\% always recycle, a rather disappointing proportion (63\%) never recycle. A more encouraging results are those in higher income bracket which found that the number people who recycle 'most of the time' and 'always recycle' are almost equally divided. This can be explained by the fact that recycling is not done by the people themselves rather the maids whom they employed.

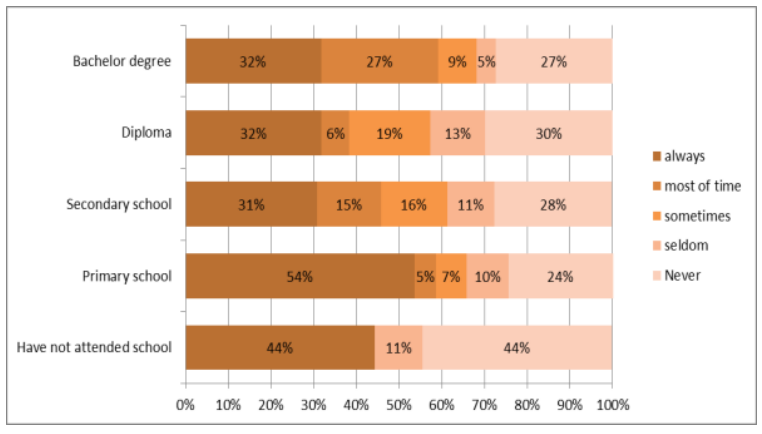

Figure 5. Frequency of separating waste by education level

While most studies do not consider ethnicity, it is suggested that in a multi-ethnic society like Malaysia should consider whether such demographic variable may have an influence on recycling inclination. However, like gender, ethnicity has not shown significant correlation with recycling behaviour. Figure 7 shows that the proportion of the various ethnic group,i.e. in all categories of recycling frequency were about the same. For example, for people who always recyle , 35\% are Malay, 34\% are Chinese and $30 \%$ are Indians and these are the proportion for other categories as well except for those who 
never recyle, the Chinese are slightly higher than the other two ethnic group.This finding is consistent with the heterogeneity of distribution of recycling status among ethnic group in another study carried out in Kuala Lumpur (Jasmine and Sharifah 2012).

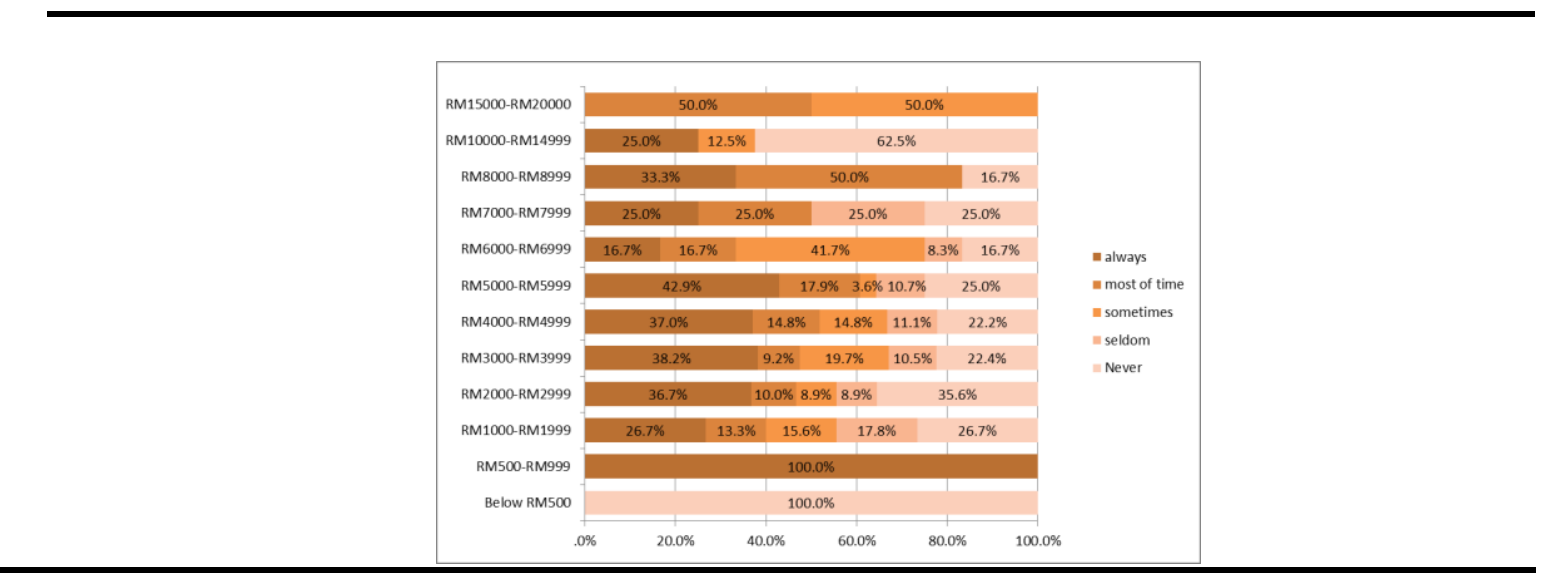

Figure 6. Frequency of Separating Waste by income group

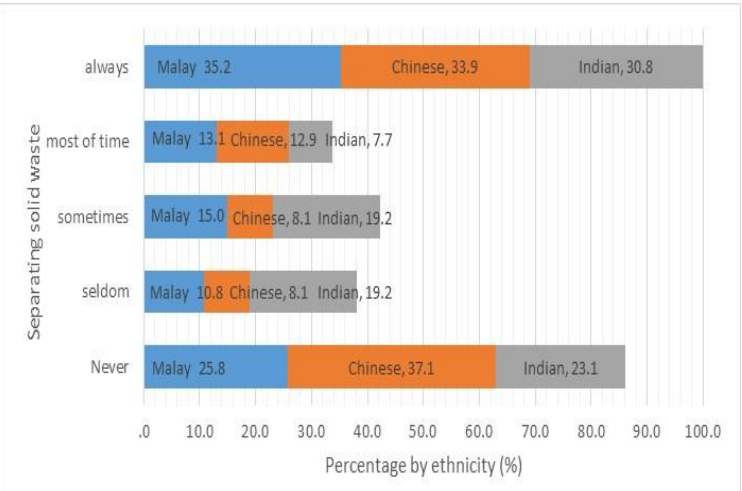

Figure 7: Frequency of separating solid waste by Ethnicity

\section{Factors Influencing Households' Participation in Recycling}

The survey also asked the respondents what drives them to participate in recycling. The motives in the environmental behaviour can be categorised into two types namely intrinsic and extrinsic. The intrinsic motivation means the desire to do something because it is enjoyable. While extrinsic motivation reflects the desire to do something because of external rewards such as awards, money, and praise (Ryan and Deci 2000). The results show that the factors which influence people to recycle are equally divided both for intrinsic motivations and extrinsic motivations.

The findings (Figure 8) showed that intrinsic motivations are environmental concerns $(33 \%)$, charity and space saving (10\%) and feeling good about doing things $(4 \%)$. 


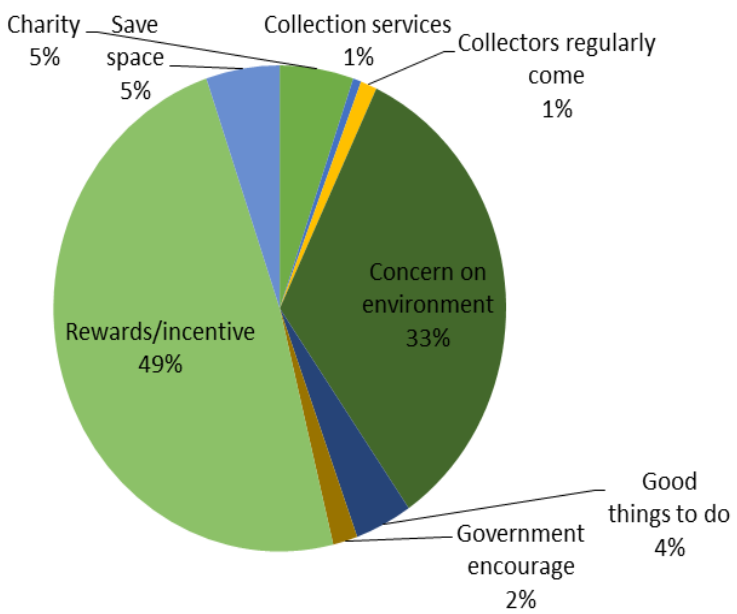

Figure 8. The motivations of recycling pratice

Almost an equal proportion of percentage are shown for extrinsic motivation i.e. rewards or incentive (49\%), regular collection services and presence of collectors $(2 \%)$ and encouragement from authority $(2 \%)$. These study shows that the people in the study area have more or less equal concern about economic benefits and environmental concerns as reasons for recycling.

\section{Reasons Not To Recycle}

Respondents are also asked on why they do not participate in recycling (Table 2), the reasons given are divided into four categories namely household issues or individual behaviour $(78 \%)$, service or location situational barrier $(15 \%)$, attitudes or motivation barrier (4\%) and information or knowledge barriers (3\%). Many reasons are given by respondents on household issues. The main reason is lack of time and busy $(65 \%)$,followed by lack of material to recycle $(24.7 \%)$, laziness $(5.59 \%)$, lack of space $(2.59 \%)$ and there is nobody else at home $(2.6 \%)$.

Table 2: Reasons Not To Recycle

\begin{tabular}{lllll}
\hline Reasons & Attitudes & $\begin{array}{l}\text { Household } \\
\text { issues/individual } \\
\text { behaviour }\end{array}$ & $\begin{array}{l}\text { Information/ } \\
\text { knowledge }\end{array}$ & $\begin{array}{l}\text { Services/location } \\
\text { situational }\end{array}$ \\
\hline Lack of facilities & - & - & - & $100.0 \%$ \\
Lack of information & - & - & - & - \\
Lack of space & - & $2.59 \%$ & - & - \\
Laziness & - & $5.19 \%$ & - & - \\
No awareness & $25.0 \%$ & - & - & - \\
No time/busy/messy & - & $65.0 \%$ & - & - \\
Not at home & - & $1.30 \%$ & - & - \\
Not enough materials to recycle & - & $24.70 \%$ & - & - \\
Not interested & $75.0 \%$ & - & - & - \\
Not many people at home & - & $1.30 \%$ & $100.0 \%$ & $100.0 \%$ \\
Total & $100.0 \%$ & $100.0 \%$ & & \\
\hline
\end{tabular}

Under the category of situational / services, most people cited lack of facilities. However, under the attitudes categories, the majority of respondents $(75 \%)$ are not interested in recycling at all and not aware on recycling benefits (25\%). Lack of information also was highlighted as reason for those who do not participate in recycling. 


\section{Conclusion}

Solid waste management in Malaysia is hampered by problems such as insufficient facilities, weak enforcement, ineffective policy implementation and lack of technology (Agamuthu, 2009; Fauziah SH, 2004). In recent years, reducing and recycling household waste has become increasingly imperative because waste generation has been increasing due to the increase in population and economic development. Resources as land for landfill had becoming scarce, making recycling not only sensible but essential. Although there is wide-spread public support for reducing and recycling of household waste, this is not reflected in participation levels in Iskandar Malaysia. An important finding from the present study indicates a positive relationship between age and frequency of recycling. Elder people are found to be more active in recycling compared to the younger ones. This is consistent with the findings from many other studies which also reveal that older households are more likely to participate in recycling activities. Thus there is need to encourage youngster to get interested and actively involved in the recycling activities.

Unfortunately, the study on the relationship between income and education with recycling activities does not concur with previous research. This study also reveals that ethnicity does not have an influence on decisions to recycle. Thus, any initiatives by the government will not have to be based on such demographic variable. Nevertheless it is discouraging to see that most people recycle because of economic benefits although environmental concerns are cited as the motive. Since respondents also cited lack of facilities as a reason for not participating, the authority should provide more facilities and services, at the same increase knowledge and awareness through rigorous campaigns.

\section{References}

Berglund, C. and S. Matti (2006). "Citizen and consumer: the dual role of individuals in environmental policy." Environmental politics 15(4): 550-571.

Bowman, N., et al. (1998). "Sustaining recycling : identification and application of limiting factors in kerbside recycling areas." International Journal of Sustainable Development \& World Ecology 5(4): 263-276.

Callan, S. J. and J. M. Thomas (1997). "The impact of state and local policies on the recycling effort." Eastern Economic Journal 23(4): 411-423.

Duggal , et al. (1991). "Recycling : An Economic Analysis." Eastern Economic Journal(Summer ): 351-358.

Garces, C., et al. (2002). "Urban waste recycling behavior: antecedents of participation in a selective collection program." Environmental management 30(3): 378-390.

Jenkins, R. R., et al. (2003). "The determinants of household recycling: a material-specific analysis of recycling program features and unit pricing." Journal of environmental economics and management 45(2): 294318.

Jesson, J. K. and I. Stone (2009). A review of barriers to kerbside recycling household waste in the UK.

McDonald, S. and C. Oates (2003). Reasons for non-participation in a kerbside recycling scheme. Resources, conservation and recycling. 39: 369-385.

Oskamp, S., et al. (1991). "Factors influencing household recycling behavior." Environment and Behavior 23(4): 494-519.

Ryan, R. and E. Deci (2000). "Intrinsic and Extrinsic Motivations: Classic Definitions and New Directions." Contemporary educational psychology 25(1): 54-67.

Singhirunnusorn, W., et al. (2012). Household Recycling Behaviours and Attitudes toward Waste Bank Project: Mahasarakham Municipality.

Tonglet, M., et al. (2004). " Using the Theory of Planned Behaviour to investigate the determinants of recycling behaviour: a case study from Brixworth, UK." Resources, Conservation and Recycling 41(3): 191-214.

Zamali, T., et al. (2009). "An Overview Of Municipal Solid Wastes Generation In Malaysia." Jurnal Teknologi 51(F): 1-15. 